5 Maybourn, R. (1972): Cost benefit and related factors. I.E.E. Conference, No. 87, p. 22:

6 Carney, Piercy, Beattie and Wylie (1972). Presentation requirements and errors. Letters published in Shipping World and Shipbuilder, January, March, April, June and September.

\title{
Some further Comments on the Regulations for Preventing Collisions at Sea, $197^{2}$
}

\author{
Captain F. N. Hopkins
}

Having read with great interest the comments of Captain F. J. Wylie in the July 1973 issue of the Journal, and moreover found himself in complete sympathy with the views expressed, the present writer, who shares Captain Wylie's disappointment and apprehension with respect to the construction of the 1972 Rules, offers some further comments as follows.

The 1910 Articles, which as Captain Wylie says employed a minimum of verbiage, were written in impeccable English, were free from ambiguity and possessed such a rhythm that they were easy to learn by heart and remember. Whether the ability to repeat them by heart was commendable is perhaps open to question, but the fact remains that Masters and officers of British merchant ships who were required to have that ability were never any the worse for it. It is realized that in those pre-radar days ships were generally much slower than they are today and the whole tempo of life was more relaxed, but even so one feels that there were fewer cases involving disregard of the Rules than there have been in more recent times. The comparative simplicity of the Rules and the fact that they were better understood may well have had much to do with that.

The 1948 Rules lacked the rhythm of the previous Articles so that learning by heart dropped out of fashion, whilst the I 960 Rules were even more prolix. Such is progress! However, in both those sets of Rules the standard of English employed was beyond serious criticism.

Regretfully, the same cannot be said of the 1972 Rules. In addition to the faults to which Captain Wylie has drawn attention there are numerous weaknesses, some of which are shown below.

In Rule 3 (i) and elsewhere a newly coined word 'underway' has replaced the former expression 'under way'. 'Underway' is a noun form like railway, seaway, or carriageway and conjures up a vision of some kind of subway, underpass or underground passage. Surely it would be better to say that 'a vessel is under way (adverbial) when she is not at anchor, or made fast to the shore, or aground" rather than 'The word "underway" means, \&c.'.

In Rule 7(a) the word 'if' in the first sentence should be 'whether', although 'If' is correctly used in the second sentence. The same fault is repeated in Rule $\boldsymbol{\eta}$ (d).

Looking at Rule $10(\mathrm{~g})$ one is tempted to ask how a vessel can anchor in something so abstract as a scheme. Presumably the intention is to recommend that a vessel shall so far as is practicable avoid anchoring in an area in which a traffic scheme is in operation. 
The wording of Rule I4(b) is vague and unsatisfactory and compares most unfavourably with the much clearer wording of Rule i 8 of the I960 Rules.

On reading Rule 19 (d) one wonders what it is that a vessel shall determine if a close-quarter situation is developing. Supposedly what is meant is that 'A vessel which detects by radar alone the presence of another vessel shall determine whether a close-quarter situation is developing and whether risk of collision exists'.

Rule 2 I (b) shows scant regard for grammar, beginning with a plural subject followed by a singular verb. Instead of the ugly phrase "'Sidelights" means' it would be an improvement to say "'Sidelights" shall consist of, \&c.'

In paragraph 6 of Annex I there are three references to 0.6 metre and in paragraph $\mathrm{I}$ of Annex II there appears the equally jarring 0.9 metre. This reads very badly and the measurements would be much better expressed as $60 \mathrm{~cm}$ and $90 \mathrm{~cm}$ respectively or, to be consistent with the dimensions of bell mouths given in paragraph 2 of Annex III, as $600 \mathrm{~mm}$. and $900 \mathrm{~mm}$.

Is it too much to hope for that before these 1972 Rules become law they can be amended where necessary to remove the existing faults?

As Captain Wylie so rightly points out, if the existing English version is going to be used as the basis for translation into other languages there certainly will be dangers ahead unless something is done beforehand to improve the text.

\title{
The Log-books used by Ships of the East India Company
}

\author{
W. E. May
}

WHEN in 1877 Clements R. Markham edited The Voyages of Sir James Lancaster $K t$ to the East Indies he remarked that the first log-book with printed headings was that used by Captain Reddell on his voyage in the Samuel \& Anna in 1702-3. He does not say that this became standard practice in the ships of the East India Company but it would seem that some of his readers thought that this must have been the case. In The Art of Navigation in England in Elizabethan and Early Stuart Times David W. Waters refers to the Samuel \& Anna log and follows it with the comment: 'The logs of British warships were still ruled and captioned in manuscript in the eighteenth century.'

This first printed $\log$ is preserved in the India Office Library (L/MAR/A.CLXXI). It is laid out to take two days to a page, headed: 'A Journal in the......from......towards......'. For each day there are narrow columns headed ' $H$ ' (hours), ' $K$ ' (knots), ' $F$ ' (fathoms), 'C' (course), and ' $W$ ' (wind), followed by a wide unheaded column for remarks. Near the bottom of the wide column is space for working out the latitude and variation thus:

$\begin{array}{ll} & \mathrm{d} \mathrm{m} \\ \text { Zenith Distance } & \text { Magnetical Amplitude } \\ \text { Declination } & \text { True Amplitude } \\ \text { Latitude by observation } & \text { Variation }\end{array}$

